\title{
Analysts, firms pour cold water on SNP Consortium
}

In mid-April, formation of the SNP Consortium was finally announced. After almost a year of discussion and negotiation, 10 major pharmaceutical companies and five leading publicly funded genomics institutes have come together in a $\$ 45$ million, two-year project that aims to identify, map, and put into the public domain hundreds of thousands of human singlenucleotide polymorphisms (SNPs). At least in its current form, which is much reduced from earlier projections, a number of biotechnology stock analysts believe the SNP Consortium carries little threat to commercial prospectors.

A report from Hambrecht \& Quist (New York) issued in March concluded that the SNP Consortium would not mount a significant challenge to specialist genomics companies such as Genset (Paris), InCyte (Palo Alto, CA), and Celera (Rockville, MD). H\&Q considered that several operational and project management issues could reduce the effectiveness of the consortium. "There has been no academic lead venture that has ever been competitive with the commercial operations," says H\&Q's Robert J. Olan. "It's a significant amount of money for the academic centers," he says, but for the companies, the main advantage of consortium membership is "in building relationships." A report from BancBoston Robertson Stephens (an international investment banking firm) echoes this doubt about the effectiveness of pharmaceutical consortia and public/private collaborations, commenting that "the history of [such groups] has not been met with ringing success."

The 10 pharmaceutical companies in the consortium are AstraZeneca, Bayer, BristolMyers Squibb, Hoffmann-La Roche, Glaxo Wellcome, Hoechst Marion Roussel, Novartis, Pfizer, Searle, and SmithKline Beecham. For a rumored $\$ 3$ million ( $\$ 15$ million for Wellcome), the members secure a place on the steering committee. The companies will not themselves undertake SNP identification or mapping. That will be performed by four of the world's leading public genomics centers: the Whitehead Institute (Cambridge, MA), Washington University School of Medicine (St. Louis, MO), Stanford Human Genome Center (Stanford, CA), and the Sanger Centre (Hinxton, UK). The Cold Spring Harbor Laboratory (Cold Spring
Harbor, NY) will coordinate the mapping and bioinformatics aspects of the project.

According to David Bentley, head of human genetics research at the Sanger Centre, the organizational model for the SNP Consortium is the publicly available expressed sequence tag (EST) database that was set up at Washington University and funded by Merck (Whitehouse Station, PA) as a foil to commercial EST databases at companies such as InCyte and Human Genome Sciences (Rockville, MD). Alan Williamson, who, as head of R\&D at Merck at that time, convinced his management colleagues to back the EST scheme, has also been instrumental in steering the consortium along the path of publicprivate collaboration. Bentley says that more industrial members could join the consortium. "This is not an exclusive club," he says. "The more resources we have, the more SNPs we can map."

The consortium's "scientific business plan" is to map 100,000 SNPs by the end of 1999 and approximately twice as many in the following year. Bentley says that, in effect, around 35,000 SNPs have already been mapped because they occur in thoroughly sequenced regions of the genome. The plan is to map a further 115,000 or so by alignment to subsequent sequence data by the end of the project.

Beyond getting the job done a little quicker, however, it is unclear what incentives there are for new industrial members to join the consortium. There will, says Bentley, be no prior disclosure of mapped SNPs to industrial partners before the results are published on the internet. The SNPs will not be patented by the consortium. And it will be impossible even for the companies to suggest which parts of the genome they might like explored first. This is simply because the institutes will take a random approach to identifying the SNPs.

Indeed, the approach to SNP identification is one of the main technical differences between the consortium and the company that is widely accepted as the current leader in SNP mapping, Genset. The sequencing and mapping centers in Stanford, Cambridge, St. Louis, and Hinxton will randomly amplify sequences and look for differences that occur in DNA from any two people. The quality control constraints on the data are that the polymorphism must occur in a region of high-quality sequence data (less than 1 errors per 10,000 base pairs) and not in a region of repetitive DNA. In contrast, in identifying 60,000 or so "biallelic markers" for its SNP map, Genset samples 10 people representing a broad ethnic diversity and selects only those polymorphisms where there is at least a 3:7 ratio of the two forms. The company argues that polymorphisms that occur in $2: 8$ or $1: 9$ ratios are less likely to be as useful in the subsequent multifactorial association studies that are the raison d'être for Genset's and other company's interests in SNP mapping.

The other main difference in the technical approaches is in the mapping method. The SNP Consortium's markers will be mapped by post hoc alignment to the full human genome sequence generated in the public sector. Mapping, therefore, depends on sequencing efforts. Genset locates its markers with reference to its proprietary bacterial artificial chromosome (BAC) physical map. Even though its stated target of 60,000 SNPs would give it a lower average density than the consortium's 150,000 SNP map, Genset's markers may be more evenly spread. It can also be argued that the company can switch its mapping efforts to parts of the genome of particular interest to its clients.

Even though Genset's ADR stock price has gradually drifted from a high above $\$ 35$ in June 1998 to around \$16 in the first quarter of 1999, Genset's chief financial officer, Debra Smeltzer, is unphased by the news of the consortium. She points out that the $\$ 45$ million budget of the consortium is only around the same order of magnitude as Genset has used in preparing its SNP map over the past several years. Given the company's earlier start, she estimates that Genset "still has a two to three year lead." Furthermore, she says that a SNP map is just the start of the gene discovery process. H\&Q's Olan agrees. "It's the pharmaceutical companies' burden to make sense of the SNPs [from the consortium project] whereas Genset provides a package where the SNPs it identifies have already been through diseaseassociation studies."

Olan's colleague, Richard van den Broek, believes that the existence of the consortium may even work to the advantage of companies such as Genset. "It's going to be a collection of maybe five or six SNPs that point to the underlying cause of complex diseases, not just one. If the consortium effort turns up two that the private companies don't have, it's the companies that will have the full set."

John Hodgson 